\title{
A New Breakthrough of Traditional Handicraft Culture in "Internet + " Background
}

\author{
Chang-long LIU and Xiao-fei HAN ${ }^{*}$ \\ Linyi University, Linyi, China \\ *Corresponding author
}

Keywords: "Internet +", Traditional handicrafts, Linshu Liubian, Tradesmanship.

\begin{abstract}
Traditional handicrafts have undergone a thousand years of changes in the long history of development in our country, closely related to our lives. It represents the cultural heritage of generations of craftsmen. Meanwhile, it has a very high economic value in contemporary society. This article is based on a variety of features of the Internet + traditional handicrafts, analyzing the development opportunities and challenges of the traditional manual culture in the Internet environment, and takes Linshu Liubian as the entry point, analyzing its development. Finally, I give some advice for the development of traditional handicrafts under the "Internet +" environment.
\end{abstract}

\section{“互联网+”背景下传统手工文化的推广新突破 \\ 刘长龙, 韩小菲 \\ 临沂大学, 临沂, 中国 \\ 通讯作者}

关键词: “互联网+”; 传统手工文化; 临沭柳编; 匠人精神

摘要：传统手工文化在我国文化发展的历史长河中历经千年更迭，与我们的生活息息相关， 代表着一辈又一辈匠人的文化传承, 在当代社会也具有极高的经济价值。本文依据 “互联网+” 传统手工文化的多种契合点, 分析传统手工文化在互联网背景下的发展机遇和挑战, 并以临 沭柳编为切入点, 分析其发展情况, 最终为 “互联网+” 背景下传统手工文化的发展提出建议。 随着时代的不断进步，科技的不断创新，人们享受着日新月异的生活，同时感受着智能化带 给我们无数的便捷。与此同时, 面对高效率智能机械的普及, 快餐式文化的泛滥, 传统手工 文化开始在这前进浪潮中慢慢淡出人们的视野。事实上传统手工文化除了自身带有深刻的文 化内涵之外, 还能够给人们带来高额的经济收益, 具有极高的发展与传承价值。

\section{1. “互联网+”与传统手工文化}

\section{1 “互联网+”}

“互联网+”代表着一种新的经济产业形态, 它指的是依托互联网信息技术实现互联网与传 统产业的联合, 以优化生产要素、更新业务体系、重构商业模式等途径来完成经济转型和升 级。利用互联网多种优势特点, 与所“+”的不同产业进行融合, 产出更多的经济效益, 在新时 代迸发出更强大的活力。

\section{“互联网+”具有以下几点优势:}

1. 人口基数大。在最近公布的第 40 次《中国互联网络发展状况统计报告》中，截至今年 6 月, 我国网民规模达到 7.51 亿, 半年共计新增网民1992万人，占全球网民总数的五分之一。 新增网民呈现两极化趋势, 互联网逐渐向低龄和高龄人群渗透。 
2. 即时性强。互联网的出现在一定程度上打破了时间空间上的限制，信息的分享更为方 便快捷, 人们能够依靠互联网即时获得自己所想要得到的信息。

3. 信息传递便捷。互联网催生出多种社交平台和软件, 人们交流更加流畅迅速, 满足了 人们在互联网大时代背景下以多种需要为基础的信息传递。

4. 资源整合性强。互联网平台信息传存量巨大，有价值的资源信息被多种平台所整合， 人们获得想要的信息渠道更加多样。

\section{2 传统手工文化}

手工艺是我国传统文化的一个重要组成部分。手工艺是指以手工劳动进行制作的具有独 特艺术风格的工艺美术，手工文化便是孕育其中的特殊属性。临沭柳编、烟台剪纸等都是传 统手工文化宝库中无可替代的一件瑰宝，这些传统手工文化无不为当地带去了巨大的经济效 益与沉甸甸的荣誉。而传统手工艺的生产过程以及使用过程中依附于特定的文化、宗教、信 仰等人文环境, 与民风民俗紧密相连, 成为了区域文化的载体。但面对大批量工业机械化方 式生产方式冲击, 传统手工艺的衰落是现代社会转型的必然产物, 因而手工艺的复兴必须面 对现实, 响应时代需求, 不断推陈出新,对自身发展重新进行定位, 寻求自身新突破。

\section{3 “互联网+传统手工文化”}

互联网让这个世界变得越来越小，“互联网+”则拉近了各行业与互联网之间的距离，在与 传统手工文化的结合在不仅拉近消费者与柳编市场的距离, 同时拉近了手工艺人与对传统手 工文化热爱者心与心的距离。“互联网+”使得传统手工文化与人们之间具有了互动性, 人们借 助“互联网+”认识传统手工文化, 传统手工文化传承者借助“互联网+”去介绍传统手工文化。 互联网作为信息载体, 时代发展的信息无不映射在互联网之中，传统手工文化匠人通过互联 网接收时代所要传递的信息结合自身创新思维, 对传统手工艺品进行改良, 创作出更多贴近 生活手工艺品。

互联网带给传统手工匠人诸多优势的同时，也是对匠人的一项特殊“考验”。传统手工匠 人大都是从老一辈人手中学得的手艺, 思想较为僵化, 思维无法跟上生活发展步伐, 创新较 少。现代的年轻人大多不愿继承手艺, 导致匠人年龄普遍偏大, 而其对于互联网这种较为新 鲜的方式又较为排斥, 这是导致传统手工文化淡出人们视野的一个重要原因。

\section{2. 临沭柳编现状}

\section{1 临沭柳编发展历史}

传统柳编手工艺存在时间之长, 几乎经历了人类社会发展的各个历史阶段, 它伴随着人 类的生产与生活实践活动而发生、发展, 它的存在形式代表中国传统手工艺造物活动的某种 样态与规律。山东作为我国的文化大省, 齐鲁文化众星璀璨, 临沭柳编文化就是其中一颗夺 目的 “明珠”。临沭柳编文化作为山东优秀传统文化的分支, 经过了岁月长河的洗礼, 仍然在 现代社会里保持释放着旺盛的生命力。临沭县是国内最大的杞柳种植和加工基地, 享有 “中国 名特优经济林杞柳之乡” “全国白柳基地县” 等称号。临沭柳编现已被评为省级非物质文化遗 产，1973 年临沭县柳编制品实现了首次出口, 因此打破了我国柳制品的出口空白。正因临沭 柳编文化不断呈现出勃勃生机的发展态势, 临沭县获得了“中国柳编之都” 的美誉, 柳编已成 为临沭县一抹不可或缺的文化色彩名片。“南走北走, 不如在家编筐打柳”, 这句被临沭人民 广为传唱的民谣, 也折射出了柳编在临沭县非同一般的经济价值。

\section{2 面临问题}

为深入了解临沭柳编这一传统手工文化在市级城市不同年龄段人群的影响力, 笔者撰写 调查问卷并发放。此次问卷线上线下共发放200份, 实际收回164份。 


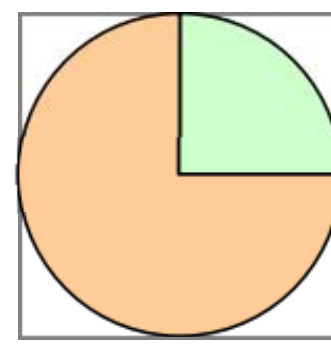

口了: 20:

图1 临沭柳编了解程度

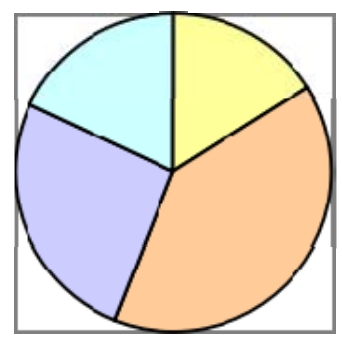

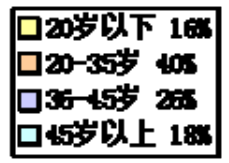

图2 接受调查年龄段

分析：从图1可以看出, 75\%的人不知道临沭柳编, 只有 $25 \%$ 的人知道临沭柳编。临沭柳 编文化市场正处于一种市场空缺的状态，大众普遍对临沭柳编认知度相对较低。

分析：(1)通过图二可以看出, 接受我们调查的人群在20岁以下的占18\%, 在20-35岁的占 $44 \%$ ，在36-50岁的占 $22 \%$ ，在50岁以上的占 $16 \%$ 。

(2)20岁以下的消费者对柳编工艺品感兴趣, 遇到感兴趣的事物会参与到设计、宣传之中, 不断创新, 不断探索。20-35岁的消费者收入较稳定, 满足了人们的基本生活需求, 对“绿色 消费”观念的顺应以及对目前田园风格时尚追求的满足愿意了解柳编相关文化。并且大多数消 费者有了自己的孩子, 培养孩子的艺术情操, 让学生充分领悟传统的鬼力, 知晓、热爱、学 习和传承“非遗”文化。36-45岁的消费者更加重视对孩子的多方面传承教育。45岁以上的消费 者大多都知道柳编产品，对传统艺术有一定的情节。

由此对临沭柳编文化当前面临问题进行SWOT分析。

1. 内部劣势

(1) 柳编是中国传统的手工艺品, 知名度不高, 知道柳编的人很少, 知道临沭柳编的人更 少, 这增加了传统柳编文化的宣传推广难度。

(2) 柳编手工艺人普遍年龄偏高, 文化程度低, 创新能力差, 创新品种少, 自主品种单一, 这导致当地缺乏专业的创新性技术人才, 传承难度较大。使得临沭柳编相关产品的附加值低, 创造的效益不高，从而使临沭柳编近几年的的产业发展速度异常缓慢。

(3) 由于与高效率的机械生产相比, 柳编产品绝大多数需要人工加工, 效率较低, 产量较 少, 价格较机械生产同类产品相比稍高。

2. 外部威胁

(1) 由于柳编产品对国外市场的出口依赖程度过高, 产品的消费具有较大的国际市场风 险，一旦遇到金融危机等冲击，便会无力应对，导致柳编行业的整体低迷。

(2) 随着现代科技进步与经济的快速发展, 市场上涌现出了多样的新兴文化, 而作为传统 文化的柳编呈现的方式相对单一, 因此在多元新兴文化市场的冲击下, 柳编正逐渐的消退出 大众的视线, 所以柳编在文化市场的竞争激烈程度可见一斑。 


\section{3 “互联网+临沭柳编”}

面对互联网诸多优势，传统手工业如临沭柳编紧抓机遇利用互联网进行商品售卖，同时 利用互联网所获得的相关信息, 对产品进行改革创新, 由之前简单的生活器血转向艺术品与 高档家居用品发展, 种类逐渐多样, 临沭当地政府建立中国柳编艺术馆, 建立临沭柳编官方 网站对当地柳编相关信息进行发布，给与一定的支持，销售渠道不断扩大，柳编文化开始越 来越被人们所熟知, 在人们的生活中所处可见柳编制品临沭柳编开始逐渐向品牌化发展。

\section{3. 发展建议}

通过网络搜集资料与实地考察，对互联网与传统手工文化的分析，并联系临沭柳编这一 实例所出现问题, 以小见大, 依据笔者所学知识提出以下切实可行的发展建议。

\section{1 紧抓时代机遇 深挖匠人精神}

近几年，随着国家对传统手工文化保护力度的加大，尤其是在社会上大力弘扬的“工匠精 神”, 传统手工匠人们开始受到关注。传统手工文化历经百年的发展, 技艺臻至成熟, 传统手 工匠人较多。乘着全社会“匠人精神”这股东风，为传统手工文化增进新鲜血液，弘扬手工文 化, 对这一文化概念的重新梳理, 更进一步坚定了手工文化创意品牌的意识, 充分挖掘发挥 手工文化的艺术价值与市场价值，同时提升传统手工文化及其品牌的美誉知名度，为手工文 化增进新的内涵。

\section{2 迎合时代潮流 研发高端产品}

早在建国初期，我国制定了传统手工艺发展的政策：“经济、实用、美观” [3]时代不断进 步, 人们不再仅仅关注物质生活的满足，对于精神生活的渴望也逐渐增大。手工产品目前种 类较为固定, 多为家具等用品, 新产品的方向应传承发展传统技艺, 并融合现代潮流元素, 打造新兴手工创意产业。让手工文化搭上时尚风，成为集实用、娱乐、创意、艺术等众多元 素为一体的创意产品。同时，以继承传统技艺、追随时代风尚为目标，打破传统手工制品外 观造型的单一性, 将艺术审美和创意设计相结合, 在传统手工技艺的基础上, 大胆的对手工 制品进行现代风格的雕琭设计, 通过为产品融入潮流元素, 打造产品新印象, 提高传统手工 文化的社会认知度，创新传承手工文化发展模式。在新型创意产品之上充分尊重消费者们的 不同个性与需求，并针对消费者的不同消费需求开设提供私人订制服务。

\section{3 开发文化产业 提升品牌效应}

依托传统手工文化已有的知名度，进一步集聚、梳理与整合相关手工文化、产业相关品 牌内涵, 通过品牌效应提升开展多种以手工传统文化为主题的相关产业, 如进行艺术节等活 动, 利用创意市集比赛等趣味游戏使之成为当地一年一度的文化狂欢盛宴, 利用互联网建立 相关网址对活动进行前期宣传, 在网站中分享活动盛况等。在相关文化产业发展同时带动其 他旅游产业发展。

\section{4 巧用直播平台 拓宽传播渠道}

目前直播平台中，奇人巧人越来越多，观看直播的观众开始走向两极，下到小学生，上 到六七十岁的老太太都能打开视频进行观看, 能够拥有一门手艺便可在直播平台中不断吸纳 粉丝。传统文化匠人手艺涃熟, 以临沭柳编为例, 如果进行直播编织手艺, 同时展示柳编制 品的加工过程, 向观众展现柳编制品污染小、安全可靠等优点, 不仅能够体现临沭柳编的编 织文化魅力, 同时可以进行现场售卖, 增加销售渠道。利用这种方法一方面可增加关注对与 产品的了解, 同时对手艺匠人的知名度进行提升, 有利于品牌打造和传统手工文化的传播。 


\section{5 线上互联互动 线下产业推广}

利用传统手工文化独特的技艺特点，与美院进行合作，教授传统文化的技艺并向学生征 集创意方案, 同时线上征集作品倡议信息, 线下建立手工艺术体验馆、“匠心”联盟, 吸收当 地手艺匠人加入对创意产品进行研发, 推动传统文化产品种类多方位发展。

\section{4. 结语}

本文意在深度发掘传统手工文化内涵与地方特色, 利用互联网为传统手工文化提出多条 可行性建议，帮助临沭柳编文化等传统手工文化寻找传承与发展的新模式。结合互联网为传 统手工文化的推广插上翅膀, 为手工文化的商业化寻找创意性新的突破, 为其快速发展提供 新助力, 充分运用“互联网+”思维与“互联网+”相关政策, 使传统手工文化内涵与商业相结合, 帮助手工文化的发展开辟一条新的途径, 让人们不忘传统手工文化之美, 感受传统手工文化 所独有的特殊魅力, 继续在民族繁荣文化之林中屹立长青。

传统手工文化的发展前行，需要摒弃传统思想的束缚，不断开拓创新推陈出新，尽管“互 联网+”传统手工文化的结合有着未知问题的出现, 但在互联网这一大时代背景下, 利用互联 网来不断推动传统手工文化的发展仍是势不可挡的时代潮流。

\section{致谢}

本文为2017年国家级大学生创新创业训练计划项目《予·编时“临沭柳编”文化创意工作 室》的阶段性成果之一。

\section{References}

[1] Xiaolin Li, Analysis of current situation and problems and Countermeasures of Linshu County willow industry, Modern economy, 7(2009)31-33

[2] Peisheng Shi, Fenghua Liang, Willow why big industry - Linshu willow from the traditional handicraft industry development features, China County Times, 7(2014)

[3] Yidao Zhang, On the folk art and folk custom, Research on folk art 4(2008)

Reference to a book:

[4] Jian hang, The idea of a craft, Shandong Pictorial Publishing House, Jinan, 2007

[5] Youbang Wang, Geography of Shandong, Shandong Map Publishing House, Jinan, 2000 